\title{
Attomole Quantitation Of Protein Separations With Accelerator Mass Spectrometry
}

J. S. Vogel, P. G. Grant, B. A. Buchholz, K. Dingley, KW. Turtletaub

This article was submitted to American Electrophoresis Society Meeting Pasadena, CA

October $16-19,2000$

U.S. Department of Energy

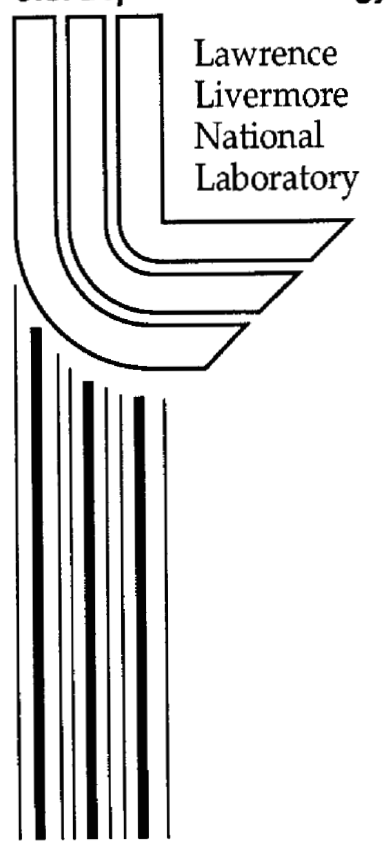

December 15, 2000 


\section{DISCLAIMER}

This document was prepared as an account of work sponsored by an agency of the United States Government. Neither the United States Government nor the University of California nor any of their employees, makes any warranty, express or implied, or assumes any legal liability or responsibility for the accuracy, completeness, or usefulness of any information, apparatus, product, or process disclosed, or represents that its use would not infringe privately owned rights. Reference herein to any specific commercial product, process, or service by trade name, trademark, manufacturer, or otherwise, does not necessarily constitute or imply its endorsement, recommendation, or favoring by the United States Government or the University of California. The views and opinions of authors expressed herein do not necessarily state or reflect those of the United States Government or the University of California, and shall not be used for advertising or product endorsement purposes.

This is a preprint of a paper intended for publication in a journal or proceedings. Since changes may be made before publication, this preprint is made available with the understanding that it will not be cited or reproduced without the permission of the author.

This report has been reproduced directly from the best available copy.

Available to DOE and DOE contractors from the Office of Scientific and Technical Information P.O. Box 62, Oak Ridge, TN 37831

Prices available from (423) 576-8401 http://apollo.osti.gov/bridge/

Available to the public from the National Technical Information Service

U.S. Department of Commerce 5285 Port Royal Rd., Springfield, VA 22161 http://www.ntis.gov/

OR

Lawrence Livermore National Laboratory Technical Information Department's Digital Library http://www.llnl.gov/tid/Library.html 
Attomole quantitation of protein separations with accelerator mass spectrometry

John S. Vogel, Patrick G. Grant, Bruce A. Buchholz, Karen Dingley, and Kenneth W. Turteltaub

Lawrence Livermore National Laboratory

Livermore, CA USA

Correspondence:

John S. Vogel

Center for Accelerator Mass Spectrometry

Lawrence Livermore National Laboratory

7000 East Avenue, L-397

Livermore, CA 94551 USA

925-423-4232

925-423-7884 FAX

jsvogel@llnl.gov

Abbreviations: AMS, accelerator mass spectrometry; AUC, area under the curve; MeIQx, methyl imidazo quinoxaline; $\mu$-PIXE, micro proton induced xray emission; $\mathrm{keV}$, kilo electron Volts; $\mathrm{MeV}$, million electron Volts

Keywords: protein, proteome, quantitation, radioisotope, accelerator mass spectrometry

Summary

Quantification of specific proteins depends on separation by chromatography or electrophoresis followed by chemical detection schemes such as staining and fluorophore adhesion. Chemical exchange of short-lived isotopes, particularly sulfur, is also prevalent despite the inconveniences of counting radioactivity. Physical methods based on isotopic and elemental analyses offer highly sensitive protein quantitation that has linear response over wide dynamic ranges and is independent of protein conformation. Accelerator mass spectrometry quantifies long-lived isotopes such as ${ }^{14} \mathrm{C}$ to sub-attomole sensitivity. We quantified protein interactions with small molecules such as toxins, vitamins, and natural biochemicals at precisions of $1-5 \%$. Microproton-induced-xray-emission quantifies elemental abundances in separated metalloprotein samples to nanogram amounts and is capable of quantifying phopsphorylated loci in gels. Accelerator-based quantitation is a possible tool for quantifying the genome translation into proteome.

\section{Contents}

1. Introduction

1.1 Quantitation of proteins in gels

1.2 Quantitation of radioactive isotopes using decay and direct counting

1.3 Accelerator mass spectrometry

1.4 Quantitation from isotope ratio measurements

2. Examples of biochemical quantitation by AMS

2.1 Limits of detection and quantitation in HPLC

2.2 Dynamic range of quantitation in 1-D gels

2.3 Background quantitation in 2-D gels

2.4 Protein identification for pharmacokinetics

2.5 Covalent binding to amino acids

3. Protein quantitation with proton beams

4. Discussion

4.1 Isotope counting

4.2 Proteome relevance

5. Acknowledgments

6. References 


\section{Introduction}

\subsection{Quantitation of proteins in gels}

The current approach to linking cellular protein concentrations and genomic data includes multidimensional separation of proteins with electrophoresis, visualization of location with stain, followed by identification with various forms of mass spectrometry[1-3]. These three technologies are continually refined, aiming for greater sensitivity in understanding the genome translation to functioning proteome. Analytic quantitation of isolated protein has not kept pace nor advanced as far. The current state of the art depends on techniques that matured 25 to 50 years ago, with enhancements due primarily to miniaturization and automation. Total amino acid analysis (AAA) uses complete protein hydrolysis, derivitization, and chromatography to isolate and quantify each constituent amino acid[4,5]. The amount of each amino acid is then summed to obtain the protein mass with present sensitivities to the $0.1-1 \mathrm{pmol}$ range[6]. Exchange of natural sulfur for radioactive ${ }^{35} \mathrm{~S}\left(\mathrm{t}_{1 / 2}=87.2\right.$ days $)$ in methionine residues of isolated proteins [7] quantifies multi-femtomole quantities with laborious normalizations that include AAA and knowing the methionine content of the quantified protein[8]. Densitometry of stained proteins, whether within intact gels or after dissolution or transfer from gels, is a more convenient technology that avoids the radioactive hazards and wastes of the short-lived isotopes. Significant progress in this technique is continually reported with recent emphasis in fluorophore "staining" [9-11], but it is still limited in sensitivity, precision, dynamic range, and specificity. Protein or peptide mass spectrometry requires the use of internal standards to achieve broad quantitation, despite its exquisite sensitivity using advanced techniques [12-14]. We report on experiences using accelerator mass spectrometry (AMS) to quantify ${ }^{14} \mathrm{C}$-labeled compounds bound to proteins after electrophoretic and chromatographic separations. We describe another accelerator technology that quantifies metallic species in gel-separated proteins. AMS has the potential to quantify protein amounts to sufficient sensitivity and precision for proteome analysis.

\subsection{Quantitation of radioactive isotopes using decay and direct counting}

Radioisotopes also have a long history in bioanalysis. Constructing an instrument, such as a liquid scintillation counter, that counts the products of radioactive decay is straightforward, leading to the ubiquitous decay counters in academia and industry. Decay counting is an inefficient method for quantitating radioisotopes since it is a function of the radioisotope's halflife. The efficiency $(\varepsilon)$ is acceptable for short lived isotopes as is revealed by the definition of radioactivity (A):

$$
\begin{aligned}
& A=\frac{\partial N}{\partial t}=\frac{N}{t_{1 / 2} / \ln (2)} \\
& \varepsilon=\frac{\partial N}{N}=\frac{\partial t}{t_{1 / 2} / \ln (2)}
\end{aligned}
$$

in which the fraction of quantified isotopes is in direct proportion to the fraction of the mean life $\left(t_{1 / 2} / \ln (2)\right)$ that one counts the decays. With radiocarbon's 8300 year mean life, $1 \%$ of a ${ }^{14} \mathrm{C}$ sample can be decay counted in, at best, 83 years. Accelerator mass spectrometry of ${ }^{14} \mathrm{C}$ is at least 1 million times as efficient, providing an enormous increase in sensitivity. Long lived isotopes such as tritium $\left({ }^{3} \mathrm{H}, \mathrm{t}_{1 / 2}=12.3 \mathrm{yr}\right)$, radiocarbon $\left.{ }^{(14} \mathrm{C}, \mathrm{t}_{1 / 2}=5730 \mathrm{yr}\right)$, radiochlorine $\left({ }^{36} \mathrm{Cl}\right.$, $\mathrm{t}_{1 / 2}=350,000 \mathrm{yr}$ ), or even long-lived radioiodine $\left({ }^{129} \mathrm{I}, \mathrm{t}_{1 / 2}=16\right.$ million yr) are more efficiently quantified by direct isotope ratio mass spectrometry that has been developed over the past 2 decades. AMS can quantify more than $1 \%$ of the ${ }^{14} \mathrm{C}$ in a sample in a few minutes to a precision of less than $0.5 \%$ in samples containing $50 \mu \mathrm{g}$ to $1 \mathrm{mg}$ of carbon. The nearly universal laboratory resistance to the use of radioisotopes derives from the inefficiency of decay counting, which requires the use of short lived isotopes with small shelf lives, high radiation danger to workers, and the significant cost of radioactive waste handling. These detriments are ameliorated and even 
eliminated by AMS quantitation of long lived isotopes.

\subsection{Accelerator mass spectrometry}

AMS negatively ionizes atoms from an inorganic form of the sample (a fullerene reduced from $\mathrm{CO}_{2}$ for carbon) and mass analyzes the ions to a part in 150 or more at mass 14 . AMS then uses tandem collision mass spectrometry to eliminate molecular isobars of the isotope being measured[15]. For radiocarbon, these isobars are ${ }^{12} \mathrm{CH}_{2},{ }^{13} \mathrm{CH}$, and $\mathrm{Li}_{2}$ which must undergo multiple collisions at several hundred $\mathrm{keV}$ energies or single collisions at $\mathrm{MeV}$ energies to be completely dissociated[16]. This energy is obtained through electrostatic acceleration with very high voltages. In the molecular breakup, the negative ions lose multiple electrons to become positively charged while residing at the million Volt potentials. These positively charged ions accelerate away from the potential, reaching $\mathrm{MeV}$ energies before running through more mass and energy analysis sectors. The ions are then "fingerprinted" for their exact identity by means of several common ion detectors that are familiar in nuclear and space physics experiments. The rare isotopes are quantified with no regard to their radio-stability against a normalizing ion current of the more common stable isotopes $\left({ }^{12} \mathrm{C}\right.$ and $\left.{ }^{13} \mathrm{C}\right)$. This isotope ratio is then compared to that measured for a standard with well known isotope concentration.

AMS was originally developed around 1980 for highly sensitive radiocarbon dating, and that remains its predominant use in the 50 or so facilities worldwide[17,18]. Natural ${ }^{14} \mathrm{C}$ occurs at 97.8 amol per mg of carbon in all living creatures that are in equilibrium with atmospheric sources of the isotope. ${ }^{14} \mathrm{C}$ dating with AMS extends back to about 50,000 years before the present, with samples that contain about $0.2 \%$ of the natural level, or $200 \mathrm{zmol}\left(10^{21}\right){ }^{14} \mathrm{C}$ per mg. Thus, one of the most sensitive instruments for quantitation has been used by archaeologist and earth scientists for over 20 years.

\subsection{Quantitation from isotope ratio measurements}

AMS produces an isotope ratio of the rare isotope to one of the element's stable isotopes or, equivalently, to the mass of the element in the sample. This quantitation is fundamentally different from decay counting because the radioactivity (Eq. 1) depends only on the number of radioisotopes in the sample. Quantification from an isotope ratio relies on careful "inventory" of any isotopic dilution that may occur in the isolation and preparation of AMS samples. The reason is shown by Equation 3 that defines the sample's carbon isotope ratio:

$$
R_{\text {sample }}=\frac{{ }^{14} C_{\text {natural }}+{ }^{14} C_{\text {tracer }}+{ }^{14} C_{\text {carrier }}+{ }^{14} C_{\text {conta } \min a n t}}{C_{\text {natural }}+C_{\text {tracer }}+C_{\text {carrier }}+C_{\text {conta } \min \text { ant }}}
$$

in which "natural" ${ }^{14} \mathrm{C}$ refers to the ubiquitous isotope content in the biosphere, while $\mathrm{C}_{\text {natural }}$ refers to the mass of carbon due to the primary material under study. All but one of the numerator and the denominator must be known in order to unfold the ratio. The "contaminant" components are assumed to be negligible until proven otherwise. The mass of the tracer carbon is also assumed small, in keeping with its tracer function. This equation reduces to two simple cases: a very small sample such as protein isolated by gel or an HPLC fraction $(<10 \mu \mathrm{g})$ and a large sample ( $1 \mathrm{mg}$ carbon) such as a piece of tissue or $25 \mu \mathrm{l}$ of blood. In the first case, $1 \mathrm{mg}$ of carrier carbon is added, usually as a precisely pipetted amount of a non-volatile compound in an easily evaporated solvent. The sample's ratio reduces to:

$$
R_{\text {sample }}=\frac{{ }^{14} C_{\text {tracer }}+{ }^{14} C_{\text {carrier }}}{C_{\text {carrier }}}=\frac{{ }^{14} C_{\text {tracer }}}{C_{\text {carrier }}}+R_{\text {carrier }}
$$

which is solved for the amount of tracer isotope after measuring isotope ratios for the sample and the carrier and using the known mass of added carrier. Polyacrylamide is produced from 
petroleum based chemicals and a small amount of gel containing an isolated protein can act as the carrier. $\mathrm{R}_{\text {cartier }}$ is a small subtraction from the measured sample ratio, and precise quantitation of the isotope-labeled protein depends only on knowing the mass of carbon in the excised gel spot. Acrylamide is $51 \%$ carbon, so a $4 \times 5 \mathrm{~mm}^{2}$ piece (or $5 \mathrm{~mm}$ diameter circle or $2 \times 10 \mathrm{~mm}^{2}$ band) of a $10 \%$ gel $1 \mathrm{~mm}$ thick contains $1.02 \mathrm{mg}$ of carbon, just the desired amount for an AMS sample using current procedures.

Similar simplifications are possible if the concentration of a labeled component in a few mg of tissue is quantified:

$$
R_{\text {sample }}=\frac{{ }^{14} C_{\text {natural }}+{ }^{14} C_{\text {tracer }}}{C_{\text {natural }}}=R_{\text {natural }}+\frac{{ }^{14} C_{\text {tracer }}}{C_{\text {natural }}}
$$

The ratio of tracer ${ }^{14} \mathrm{C}$ to natural carbon can be directly converted to grams of the labeled compound per gram of tissue by knowing the carbon concentration in the tissue and the specific isotope activity of the compound under study. The natural isotope ratio is obtained from control animals or human samples prior to dosing the volunteer. These levels should be close to "Modern", a unit referring to 13.56 milli-dpm, 97.8 amol or $6.11 \mathrm{fCi}$ of ${ }^{14} \mathrm{C}$ per $\mathrm{mg}$ of carbon.

\section{Examples of AMS quantitation}

\subsection{Limits of detection and quantitation in HPLC}

AMS was used in quantifying amino acid separations by HPLC over a 3 month period[23]. Each series of measurements included at least 3 samples of the carrier compound, tributyrin, which was aliquoted into eluent fractions as $50 \mu \mathrm{l}$ of a methanol solution at $40 \mathrm{mg} / \mathrm{ml}$. The methanol was removed under vacuum centrifugation and the samples prepared for AMS [19]. Tributyrin is available from several chemical suppliers and is manufactured from a variable amount of petroleum and biologically derived precursors. Tributyrin from ICN (Cat. \#103111) has the lowest concentration of ${ }^{14} \mathrm{C}$ at about $10 \%$ Modern. The ${ }^{14} \mathrm{C}$ concentrations from 24 measurements of only carrier aliquots contained $9.56 \pm 0.18 \mathrm{amol}{ }^{14} \mathrm{C}$ per aliquot. This indicates a LOD of $540 \mathrm{zmol}$ at $3 \mathrm{SD}$ and a LOQ of $900 \mathrm{zmol}$ at $5 \mathrm{SD}$. Aliquots obtained between HPLC peaks averaged to $9.11 \pm 0.24$ amol per aliquot, lower than the carrier-only samples. There is nothing in the AMS process that can remove ${ }^{14} \mathrm{C}$ selectively from a sample, and HPLC fractions must contain at least the same amount of ${ }^{14} \mathrm{C}$ as the carrier. The HPLC isotope ratios indicate a quantifiable amount of extra carbon in the samples that was not originally counted. A discussion with the experimenter revealed that the chromatography buffer contained non-volatile acetate which became incorporated in each sample. Knowing that there was exactly $1.19 \mathrm{mg}$ of carbon in the carrier fractions revealed that there was an additional $50 \pm 2 \mu \mathrm{g}$ of radiocarbon-free carbon being added to the HPLC fractions by the acetate. Correct AMS quantitation depends on control of both the radioisotope and the elemental abundances. The HPLC fractions still contained 9.6 amol, but incorrect carbon inventory led to a 5.2\% underquantitation. A fractionally Modern carrier is more desirable than a truly ${ }^{14} \mathrm{C}$ free one as a check on inclusion of unexpected carbon.

\subsection{Dynamic range of quantitation in 1-D gels}

The range of AMS quantitation is demonstrated in protein separations with gels. 1-D gel electrophoresis separated hepatic proteins that bound a common pharmaceutical, acetaminophen (also known as paracetamol) [20]. The drug was obtained with a ${ }^{14} \mathrm{C}$ label at $0.245 \mathrm{Ci} / \mathrm{mol}$ and $0.00245 \mathrm{Ci} / \mathrm{mol}(0.4 \%$ and $0.004 \%$ molecular labeling). Equal doses at $375 \mathrm{mg} / \mathrm{kg}$ were administered to mice, and liver homogenates $(\approx 360 \mu \mathrm{g}$ protein) were run on 1-D PAGE. Entire lanes were excised in $0.3 \mathrm{~cm}$ bands down $16 \mathrm{~cm}$ of the lanes. Figure 1.a shows the amount of the ${ }^{14} \mathrm{C}$ bound to proteins at both specific activities across a mass range down to $10 \mathrm{kDa}$. No proteins appeared in the gel below about $12 \mathrm{kDa}$, and the ${ }^{14} \mathrm{C}$ concentrations in those gel areas were used as the background concentration of the "carrier" gel. The 0.3 by $0.7 \mathrm{~cm}^{2}$ pieces of gel contained $2.4 \mathrm{mg}$ of ${ }^{14} \mathrm{C}$-free carbon, allowing quantitation using Equation 4. The low dose gel had $4.04 \pm$ 
0.54 amol ${ }^{14} \mathrm{C}$ per band as background in bands 48 through 51 , while the high dose gel had $48 \pm$ 22 amol per band in samples 47 through 50. The electrophoretic front had passed through these loci and was found beyond fraction 51. Gels retain higher levels than HPLC of labeled materials that traverse the gel. Solubility of labeled entities and diffusion in the buffers further raises gel background levels. Highest quantitation was $16 \mathrm{fmol}$ of ${ }^{14} \mathrm{C}(4.1 \mathrm{pmol}$ of drug) at high protein mass for the high label level. This isotope ratio was 70 Modern and is about a factor of 2 below the highest isotope levels that our AMS detector can precisely count at present. The LOQ for the low dose lane was 6.7 amol, for a quantifiable dynamic range of about 5000 for gel-AMS.

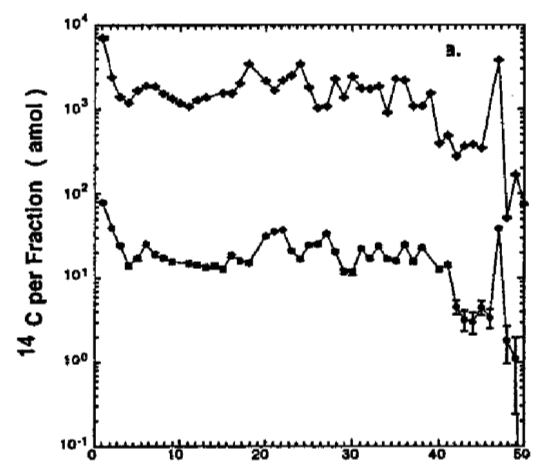

Gel Fraction
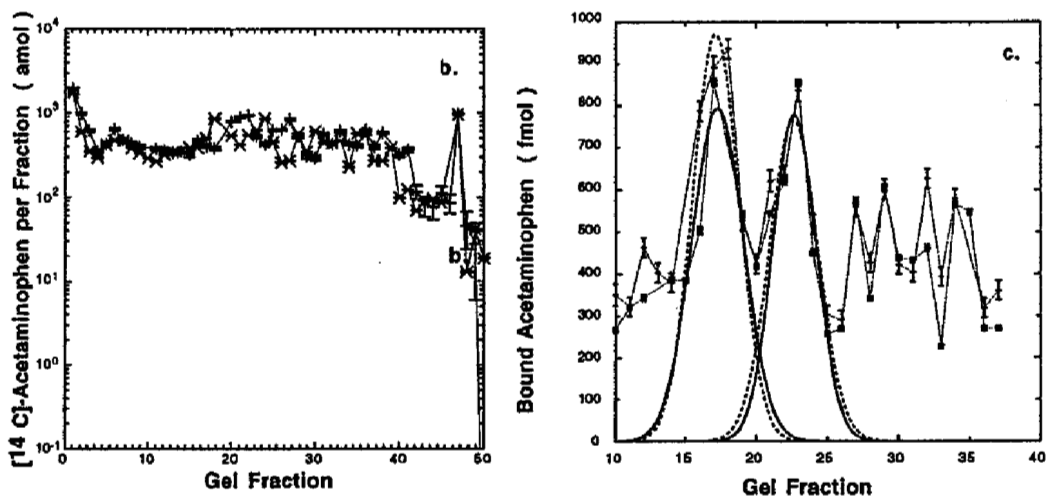

Figure 1. a.) ${ }^{14} \mathrm{C}$ content along two lanes of SDS-PAGE is plotted against sample number in $0.3 \mathrm{~cm}$ steps. Lanes were loaded with hepatic proteins from mice exposed to $\left[{ }^{14} \mathrm{C}\right]$-acetominophen at $375 \mathrm{mg} / \mathrm{kg}$ with $0.4 \%$ and $0.004 \%$ of the molecules isotope-labeled $b$.) The quantified amount of bound acetaminophen calculated from the high label $(\mathrm{O})$ and the low label $(\mathrm{X})$ cases is plotted against the sample number.

Table 1. Parameters from Gaussian fits to protein binding peaks at 58 and $44 \mathrm{kDa}$ for $0.4 \%$ and $0.004 \%$ molecular labeling by ${ }^{14} \mathrm{C}$.

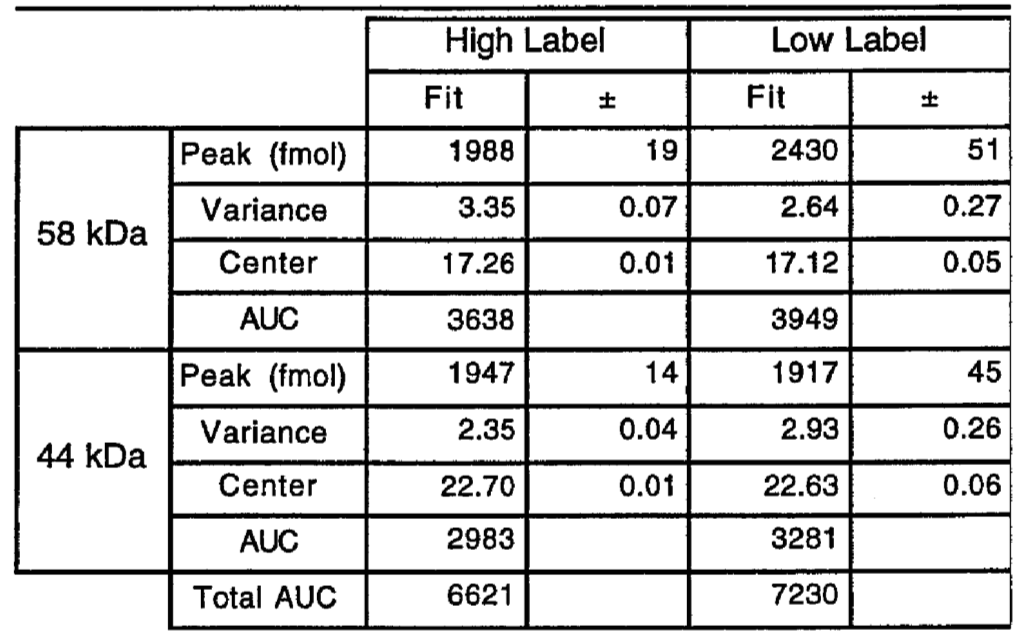

Both gels were quantified for acetaminophen binding by dividing the ${ }^{14} \mathrm{C}$ contents of each band by the labeling fraction, providing the quantitation of bound acetaminophen shown in Figure 1.b. A $1 / 2$ band offset between the lanes allowed the final low-mass peaks to align, but differential spreading along the lanes is still clearly evident, as indicated by the shift between lanes of 2 gel fractions for the $58 \mathrm{kDa}$ and $44 \mathrm{kDa}$ hepatic proteins that are known to bind the drug[21,22]. Peak alignment after the 2 fraction shift for the mid-gel data is shown in Figure 1.c. There is close alignment and equal quantitation of the protein-drug binding across the displayed range between the high and low isotopic labels. The low ${ }^{14} \mathrm{C}$ data shows greater error bars in final quantitation, representing about $5 \%$ uncertainty in the measurements. Gaussian peak shapes were simultaneously fit using error weighting to the 58 and $44 \mathrm{kDa}$ peaks for both isotope levels. Table 1 summarizes the equivalence of analyzed data obtained in experiments using $15.4 \mu \mathrm{Ci}$ and $154 \mathrm{nCi}$ per mouse, with obvious laboratory advantages in using the latter. Higher uncertainties in parameters of each peak are obtained with the lower isotope content, but peak 
definition and integration is not compromised. The area under the curves (AUC's) represent the final quantitation of the proteins and differ by less than $10 \%$. The peak variances represent about $3 \mathrm{kDa}$ spreading of the protein band from the center. Many mouse experiments use AMS sensitivity with radiative doses of about 1-10 nCi per animal.

Only a few clear bands were visible in either gel, but the AMS quantitation shows binding at fmol to amol levels across large regions of both gels. Non-specific binding to many proteins could produce the plateau out to band 40 , or there might be a fundamental error in quantifying protein binding in gels with AMS.

\subsection{Background quantitation in 2-D gels}

The wide plateaus of binding displayed in Figure 1 could be an artifact of the gel separation and quantitation by AMS rather than an indication of widespread protein binding. 2-DE-AMS was used to distinguish isotope smear from widespread protein binding. Figure 2 shows a several $\mathrm{cm}^{2}$ area of a 2-D gel of a hepatic protein homogenate after reaction with a labeled compound. Isotope quantities of $50 \mathrm{amol}$ in the lower pixels are equivalent to the lowest gel pieces in the high activity 1-D gel above. The tested area contains enough small peaks to produce a plateau when summed along the molecular weight axis. Quantitation is indicated by the isotope contents in 4 pixels of the figure. The peak pixel in this view contains about 440 amol of the label. The 25 lowest pixels contain an average of $53.3 \pm 6.4 \mathrm{amol}$ of ${ }^{14} \mathrm{C}$. This background may again arise from passage of proteins through the chosen pixels as was seen in the low mass bands of the 1-D gel. Solubilized fragments might also have spread a gel-wide non-specific signal. Individual spots in this gel can be quantitated across a 1:120 dynamic range from 85 amol (5 SD above background) to $10 \mathrm{fmol}$ of ${ }^{14} \mathrm{C}$. The total isotope load should be kept as small as possible to depress the overall gel background. The total amount of labeled protein can be restricted by either preselecting the proteins loaded or by prefiltering to remove smaller mobile fragments.

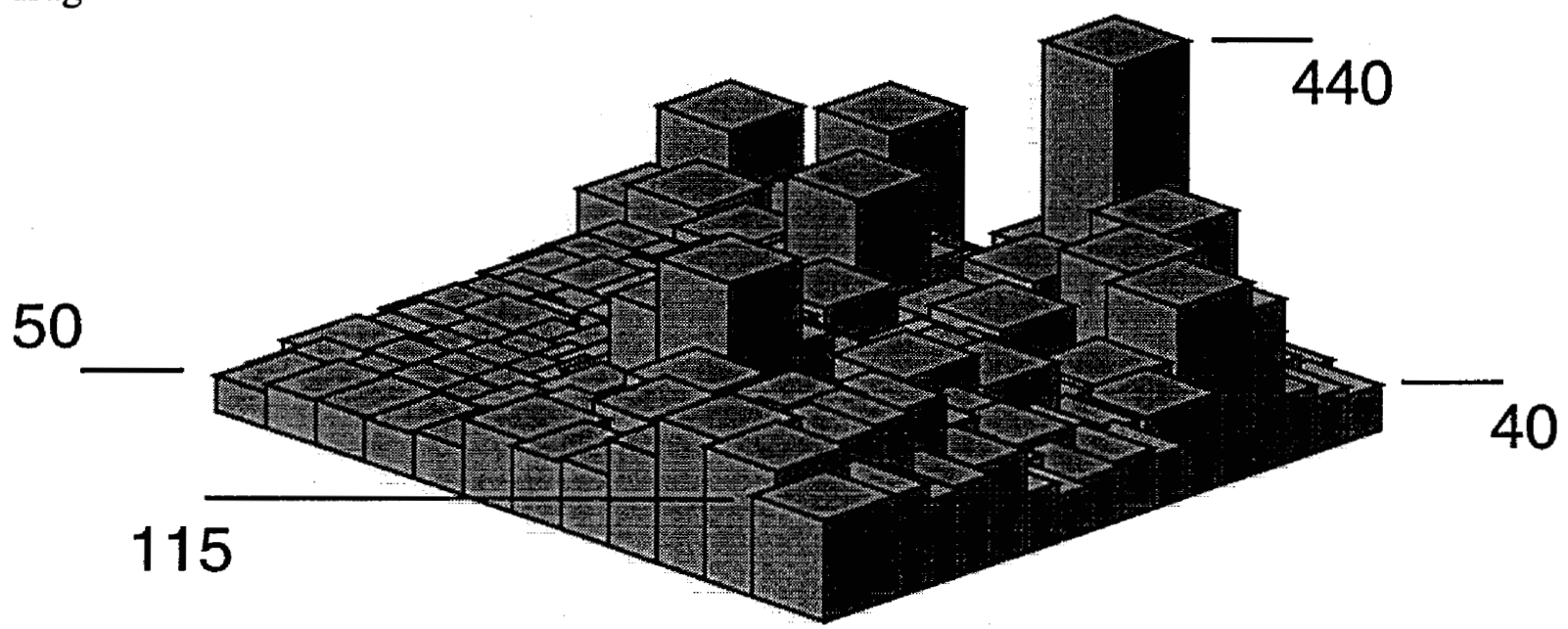

Figure 2 A section of a 2-DE was cut into $12 \times 16$ squares covering several $\mathrm{cm}^{2}$. Each of the 192 gel aliquots was quantified by AMS. Height of the pixels represents ${ }^{14} \mathrm{C}$ concentration in a $2 \mathrm{mg}$ gel piece. Four pixel heights are labeled in amol of ${ }^{14} \mathrm{C}$.

This detailed quantification of a 2-DE at sub-cm resolution is impractical for routine analysis. The 192 pixels shown here represent about 10 hours of AMS measurements and a significant fraction of a week's preparation time for a chemical technician. We are researching automated sample preparation and increasing our throughput with a new spectrometer. However, AMS is still better suited to quantifying identified proteins, but no other technology is capable of revealing the loci of proteins at the ultimate quantitation sensitivity of AMS. 2-DE with only a few peaks may be quantified by orthogonal projections or, equivalently, by 1-D molecular weight and IEF strip separations. The orthogonal properties can be sampled along both 1-D strips 
by $n$ and $m$ excised fractions respectively. Only $n$ plus $m$ measurements rather than the entire $n$ by $\mathrm{m}$ grid are then needed to quantitate proteins in a sparse set. Orthogonal 1-D strips would be sampled effectively with $\mathrm{n}$ and $\mathrm{m}$ approaching 100 , providing degenerate data on 10,000 pixels. The important task will be the quantitative isolation of significant proteins to a low enough density that orthogonal quantification leaves few unresolvable loci. Additional data for resolving degenerate loci can be obtained by AMS amino acid analysis or identification of resolved proteins at amol levels using AMS sequencing [23].

\subsection{Protein identification for pharmacokinetics}

The most productive use of AMS in human biochemical analysis has been pharmacokinetics [24-27], since low radiative and chemical doses are used. Many experiments previously reserved to rodent hosts are performed in humans to eliminate scaling uncertainties. We study the damage done to target organ DNA by heterocyclic toxins that are commonly found in cooked diets $[28,29]$. These compounds are carcinogenic to rodents and may contribute to cancer incidence in people, but the rodent data is problematic to apply to humans. An experiment determined this scaling by exposing volunteers a week prior to surgery for colon tumors to very low doses ( 0.3 and $3.3 \mu \mathrm{g} / \mathrm{kg}$ of body weight) of $\left[{ }^{14} \mathrm{C}\right]$-methylimidazoquinoxaline (MeIQx), commonly found in well cooked meats. Their blood was sampled daily before several $\mathrm{mm}^{2}$ of healthy and tumorous colon tissue were collected during surgery. The temporal binding of activated metabolites of MeIQx to circulating proteins was compared to the final level of DNA damage cause by the dose. Electrophoresis was used to determine the circulating proteins affected by the labeled compound.
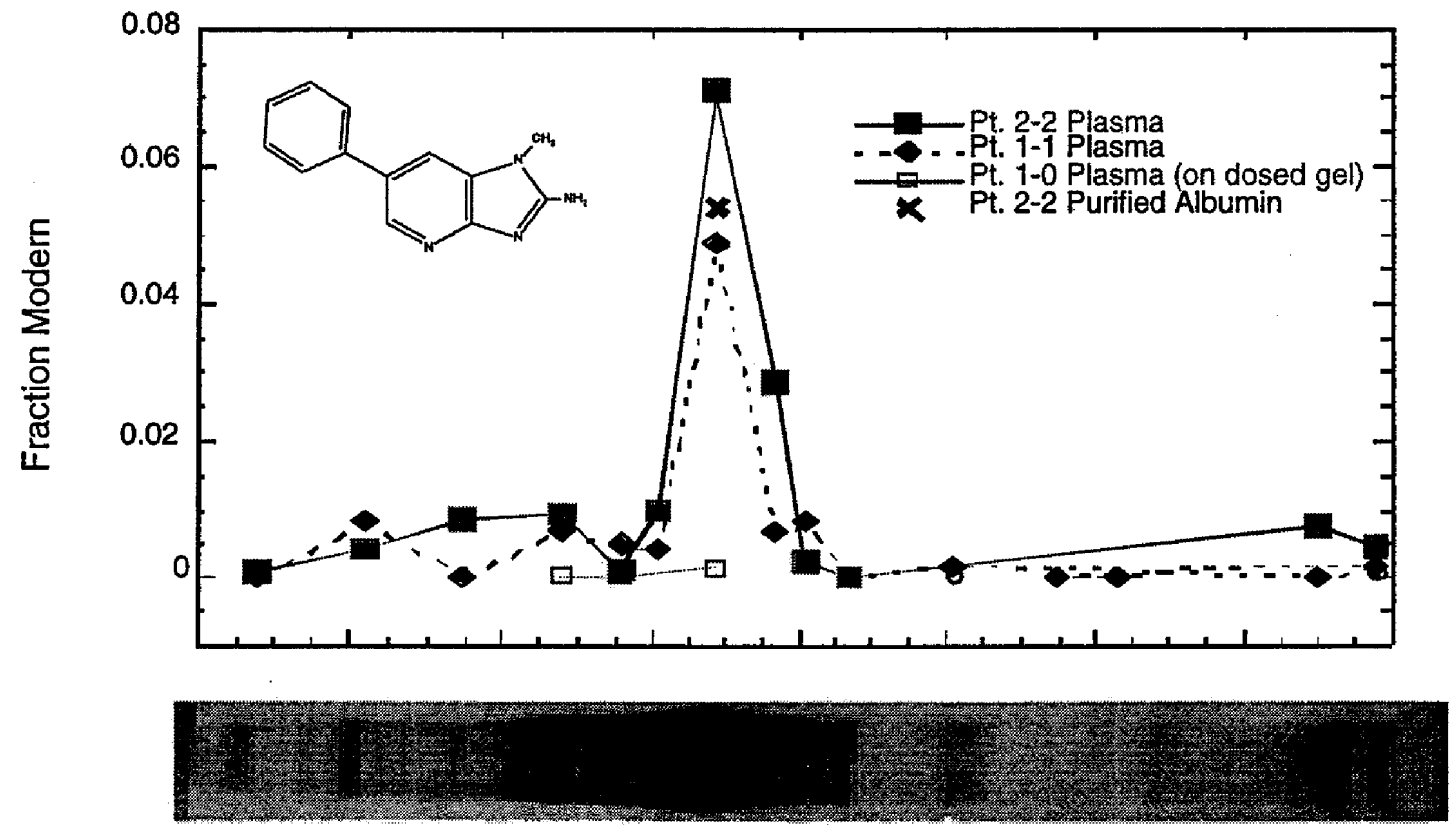

Figure 3. A gel lane of human plasma proteins that were analyzed for binding to the labeled food toxin, MeIQx, is shown with the quantified radiocarbon content. An albumin standard (X) shows that the compound binds preferentially to albumin in the two subjects shown. The peak is $7 \%$ Modern, or $70 \mathrm{amol}$ of ${ }^{14} \mathrm{C}$ per $\mathrm{mg}$ of gel carbon.

Figure 3 shows a gel lane of human plasma proteins along with the AMS quantitation of the labeled toxin bound to the proteins. Albumin dominates the plasma binding of MeIQx. This simplifies measuring the binding kinetics. An unfractionated sample of plasma directly reflects toxin activation and binding to albumin after the parent compound and metabolites have been excreted. These kinetics were quantified for 6 volunteers, among whom there was clear variation, with two showing much more rapid activation and binding. These same two showed the least amount of binding to DNA in the acquired colon tissues. The mechanism of this behavior is not yet explored, but the differences found among the volunteers hint at a way to survey for risk of 
cancer using simple blood kinetics. Electrophoresis is an adjunct in this case to simplifying the preparation of pharmacokinetic samples for AMS measurement.

\subsection{Covalent binding to amino acids}

AMS gel quantitation is used to determine the amino acid within an intact protein that is the target for covalent binding of labeled compounds $[30,31] \cdot\left[{ }^{14} \mathrm{C}\right]$-acetoacetic ester was allowed to bind to natural rabbit muscle aldolase with and without the presence of the linking agent, cyanoborohydride. Covalent binding to a lysine within a receptor region was expected. Greater overall binding was found at low ester doses for the case omitting the linking agent. The aldolase was lysed at methionines ( 3 instances in aldolase) by cyanogen bromide and the 4 peptides were separated on a $16 \%$ PAGE with tricine buffer, providing the pattern shown in Figure 4 . The masses of the 4 visible bands are (left to right) $18,12,8$, and $2 \mathrm{kDa}$. The expected receptor lysine occurs in the $8 \mathrm{kDa}$ fragment numbered 8 in Figure 4 . Figure 5 shows the ${ }^{14} \mathrm{C}$ quantitated for each excised band from 2 replicate lanes.

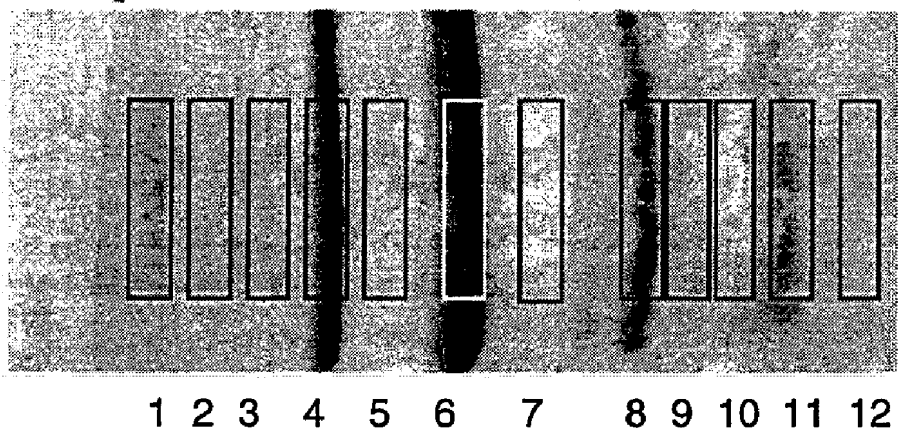

Figure 4. A tricine PAGE separation of the 4 peptides created by $\mathrm{CNBr}$ cleaving of rabbit muscle aldolase along with the 12 gel bands quantified for bound $\left[{ }^{14} \mathrm{C}\right]$-acetoacetic ester.

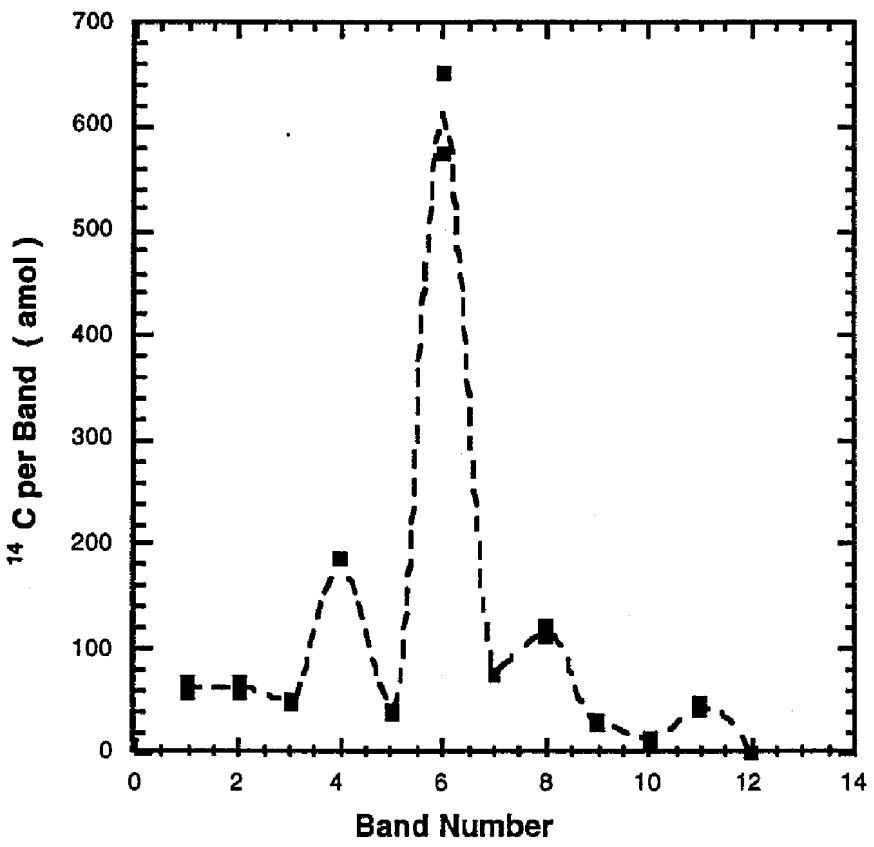

Figure 5. Quantitated ${ }^{14} \mathrm{C}$ from gel bands shown in Figure 5. Data from at least 2 independent gels is plotted for each band. Gaussian fits incorporating $4 \mathrm{kDa}$ widths were made to each peak for integration of the isotope attributable to each peptide.

Areas under peaks were integrated for each band using Gaussian fits having $4 \mathrm{kDa}$ 
widths. The data were corrected for underlying crosstalk, particularly between the 12 and $8 \mathrm{kDa}$ bands. The ${ }^{14} \mathrm{C}$ concentrations per peptide mass were then correlated with the copy number of each amino acid. The correlation fit best for tyrosine $(r>0.9)$ rather than the expected lysine $(r \approx$ 0.5 ). No other amino acids had significant correlation with the ${ }^{14} \mathrm{C}$ in each band. A reanalysis of the chemistry ascribed the binding to an unexpected reaction that occurs at a frequency of only $2: 10^{6}$ tyrosines at physiological temperatures[30]. Reliable attomole quantitation in a gel separation revealed new biochemical pathways that would not have been seen under higher concentration exposures.

\section{3. $\mu \mathrm{PIXE}$ on gels}

Micro-proton-induced-xray emission ( $\mu$-PIXE) is another accelerator based technology that characterizes proteins separated by electrophoresis in our laboratory. $\mu$-PIXE quantifies elements $(\mathrm{Z}>\mathrm{Na}$ ) by counting elementally characteristic $x$-rays emitted from a defined spatial region when the sample is struck by a known amount of accelerated protons[32]. $\mu$-PIXE analysis of thin film standards with biological samples quantifies elemental abundance to greater than 95\% accuracy [33]. The proton beam can be focused to under 1 micron in diameter for investigating detailed element distributions in single cells, isolated cellular components, or tissue slices. We used a larger beam (50 micron diameter) in scanning gels for metalloproteins. Figure 6 shows intensity plots of iron $\mathrm{K}$ xrays $(6.2-6.4 \mathrm{keV})$ created by a proton scan across a ferritin (Sigma-Aldrich) band in a gel lane and across the same protein after transfer to a nitrocellulose membrane. Major and minor iron-bearing components are seen, as well as apparent fine structure in the protein bands in both the original gel and in the transfer membrane. $\mu$-PIXE directly quantifies metal ligands bound to proteins but can also be useful in quantifying the amount of protein in the band as well as determining some post-translational modifications.

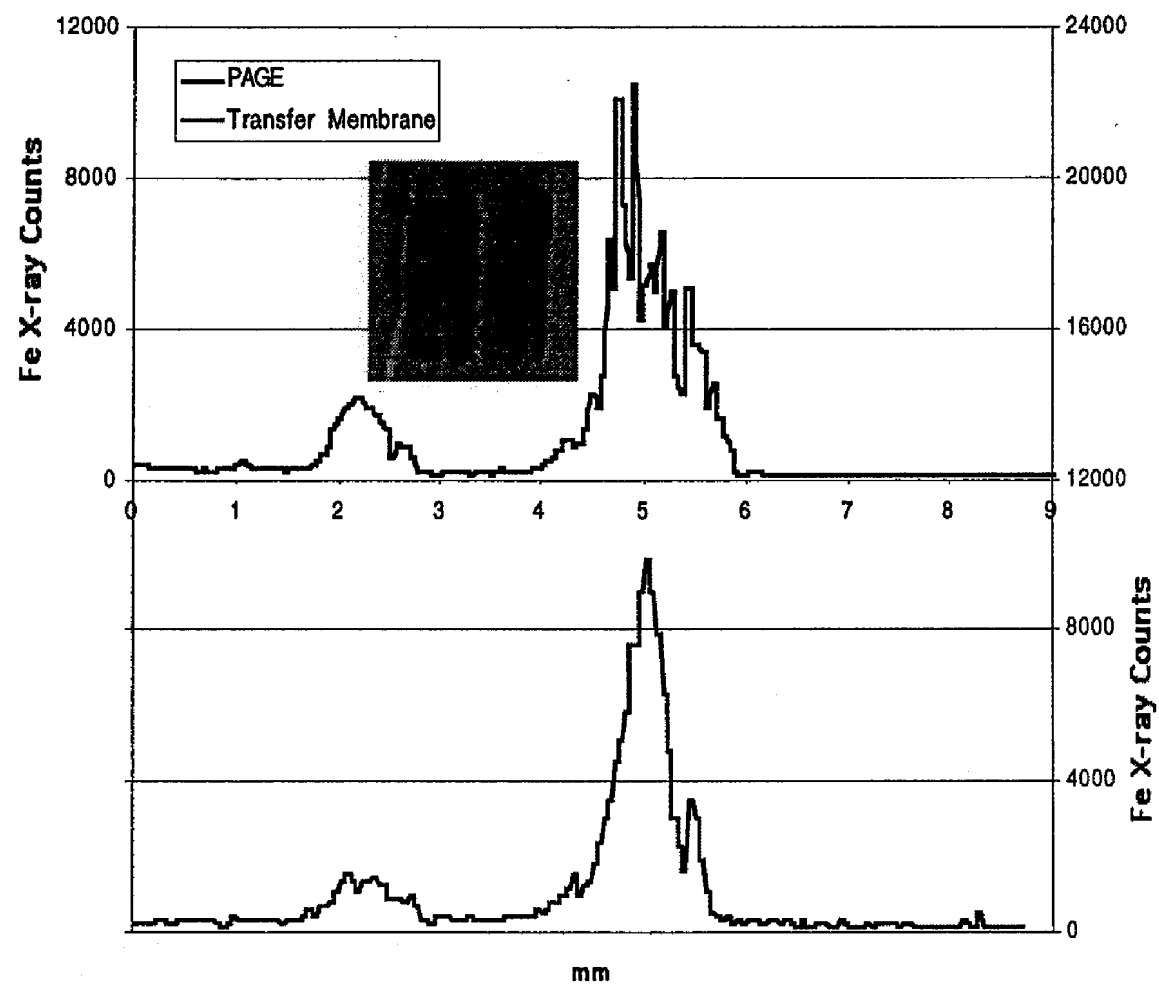

Figure 6. Iron xray counts from commercial ferritin are shown after separation by 1-D PAGE (upper trace) and after transfer to a thin membrane (lower trace). The stained protein bands are shown in insets. The major and minor peaks were scanned at 50 micron resolution and are separated by $0.3 \mathrm{~cm}$. 
The xrays produced by sulfur and phosphorus concentrations are quantified above a well characterized xray continuum at $1.9-2.1 \mathrm{keV}$ and $2.2-2.4 \mathrm{keV}$ respectively by $\mu$-PIXE. The sulfur content directly quantifies the concentration of cysteine and methionine, providing total quantification of proteins with known sequences. Phosphorylation fractions are derived directly from the phosphorus contents of a protein band. The detection limit for elements commonly analyzed by $\mu$-PIXE is 1 to $10 \mathrm{ppm}$, where the total mass analyzed includes the substrate and the protein. Thin transfer membranes thus provide greater sensitivity in quantification, but introduce uncertainty through the transfer efficiency. A few to tens of micrograms of a moderate sized protein are necessary for quantitation, which is similar to sensitivity offered by recent staining procedures [34]. $\mu$-PIXE adds protein content information, however, and, more importantly, is linear over a wide dynamic range and is independent of the protein conformation. Quantitative comparisons among widely disparate proteins are possible with $\mu$-PIXE quantitation.

Competing methods (atomic absorption spectroscopy, inductively coupled plasma-mass spectrometry, or ion chromatography) for measuring metal contents of proteins in gels or transfer membranes require considerable preparation from $\mathrm{mg}$-sized fractions. These techniques quantify bulk bands excised from a gel lane after digesting the gel matrix in stringent sample preparation schemes. The plot of Fe x-rays in Figure 6 indicates the sampling of the gel at even 1-mm would not detect the smaller structure. A wide band or large spot might contain multiple proteins that are resolvable and quantifiable by the high resolution of $\mu$-PIXE but might be blended or differentially reactive in staining. The application of $\mu$-PIXE as a tool for protein quantitation continues to be developed.

\section{Discussion}

\subsection{Isotope counting}

Unlike protein mass spectrometry coupled to electrophoresis, AMS provides only quantitation of long-lived isotope in an isolated fraction. Its "mass spectrometry" name is often confusing. AMS quantitation extends through single attomole and into zeptomole sensitivity but is only available if the isotope represents a biochemical effect to be quantified, which has been protein binding in these examples. Our institutional interests have centered on small molecule binding to macromolecules, and the quantity of a labeled small molecule is precisely obtained. AMS is easily applied to pharmacokinetics and toxicokinetics in humans and animal models using isotope-labeled drugs or toxins. The high sensitivity allows study of low doses [24], low specific-activity compounds [27], and very small samples, especially in the case of human subjects [26]. Receptor binding is also straightforward, if the target protein or entity is sufficiently separable from non-specifically bound fractions[35]. Electrophoresis (1-D, 2-D, CE, etc.), along with chromatography (HPLC, affinity, size exclusion, thin layer, etc.) have been successfully mated to AMS quantitation through fraction collection. Direct "hyphenation" of AMS with these separatory modes is also under development [36]. Work in progress also quantitates ${ }^{14} \mathrm{C}$ incorporated directly into protein through cell cultures at attomole sensitivity [23].

Attomole quantitation continues to grow in importance as analytical methods shrink to "chips" through which only very small samples can be analyzed. These technologies have detectors capable of responding to low concentration eluents, but few are capable of unbiased quantitation across a wide dynamic range. The exploitation of genomics and emerging proteomics also requires the quantitation that isotope counting can provide. The primary inhibitions to using ${ }^{14} \mathrm{C}$ in more applications revolve around the questions of radioactivity in the laboratory and the waste stream, but these arise from use of enough isotope for countable decays. AMS use ${ }^{14} \mathrm{C}$ is in the nanoCurie (kiloBequerel) range, and the wastes are well under the federal exemption on biological radioactive wastes of $50 \mathrm{nCi}$ per gram [37]. When the dose to a $25 \mathrm{~g}$ mouse is $10 \mathrm{nCi}$ and to a $70 \mathrm{~kg}$ human is a few hundred $\mathrm{nCi}$, the biological wastes cannot approach the exempted level even after biochemical isolation. 
(2) Figeys, D.; Gygi, S. P.; Zhang, Y.; Watts, J.; Gu, M.; Aebersold, R. Electrophoresis 1998, 19, 1811-8.

(3) Gygi, S. P.; Corthals, G. L.; Zhang, Y.; Rochon, Y.; Aebersold, R. Proceedings of the National Academy of Sciences of the United States of America $2000,97,9390-5$.

(4) Edman, P. Archives of Biochemistry and Biophysics 1949, 22, 475.

(5) Bridgen, J. Biochemistry 1976, 15, 3600-4.

(6) Yan, J. X.; Sanchez, J. C.; Binz, P. A.; Williams, K. L.; Hochstrasser, D. F. Electrophoresis 1999, 20, 749-54.

(7) O'Farrell, P. H. Journal of Biological Chemistry 1975, 250, 4007-21.

(8) Gygi, S. P.; Aebersold, R. Methods in Molecular Biology 1999, 112, $417-21$.

(9) Lim, M. J.; Patton, W. F.; Lopez, M. F.; Spofford, K. H.; Shojaee, N.;

Shepro, D. Analytical Biochemistry 1997, 245, 184-95.

(10) Steinberg, T. H.; Chernokalskaya, E.; Berggren, K.; Lopez, M. E.; Diwu,

Z.; Haugland, R. P.; Patton, W. F. Electrophoresis 2000, 21, 486-96.

(11) Valdes, I.; Pitarch, A.; Gil, C.; Bermudez, A.; Llorente, M.; Nombela, C.; Mendez, E. Journal of Mass Spectrometry 2000, 35, 672-82.

(12) Patterson, S. D. Electrophoresis 1995, 16, 1104-14.

(13) Skipper, J. C.; Gulden, P. H.; Hendrickson, R. C.; Harthun, N.; Caldwell, J. A.; Shabanowitz, J.; Engelhard, V. H.; Hunt, D. F.; Slingluff, C. L., Jr. International Journal of Cancer 1999, 82, 669-77.

(14) Shevchenko, A.; Loboda, A.; Ens, W.; Standing, K. G. Analytical Chemistry $2000,72,2132-41$.

(15) Nelson, D. E.; Korteling, R. G.; Stott, W. R. Science 1977, 198, 507-8.

(16) Suter, M. Nuclear Instruments \& Methods in Physics Research Section B-Beam Interactions with Materials and Atoms 1998, 139, 150-157.

(17) Vogel, J. S.; Turteltaub, K. W.; Finkel, R.; Nelson, D. E. Analytical Chemistry 1995, 67, A353-A359.

(18) Kutschera, W.; Golser, R.; Priller, A.; Strohmaier, B. Nuclear Instruments \& Methods in Physics Research, Section B (Beam Interactions with Materials and Atoms) 2000, 172, 1 - 977 .

(19) Vogel, J. S. Radiocarbon 1992, 34, 344-350.

(20) Qiu, Y. , University of California, 1999.

(21) Bartolone, J. B.; Birge, R. B.; Bulera, S. J.; Bruno, M. K.; Nishanian, E. V.; Cohen, S. D.; Khairallah, E. A. Toxicology and Applied Pharmacology 1992, $113,19-29$.

(22) Bulera, S. J.; Birge, R. B.; Cohen, S. D.; Khairallah, E. A. Toxicology and Applied Pharmacology 1995, 134, 313-20.

(23) Miyashita, M.; Presley, J. M.; Buchholz, B. A.; Lam, K.; Lee, Y. M.; Vogel, J. S.; Hammock, B. D. Proceedings of teh National Academy of Science 2001, In Press.

(24) Clifford, A. J.; Arjomand, A.; Dueker, S. R.; Schneider, P. D.; Buchholz, B. A.; Vogel, J. S. Advances in Experimental Medicine and Biology 1998, 445, 239-51.

(25) Buchholz, B. A.; Arjomand, A.; Dueker, S. R.; Schneider, P. D.; Clifford, A. J.; Vogel, J. S. Analytical Biochemistry 1999, 269, 348-52.

(26) Dingley, K. H.; Curtis, K. D.; Nowell, S.; Felton, J. S.; Lang, N. P.; Turteltaub, K. W. Cancer Epidemiology, Biomarkers and Prevention 1999, 8, 50712 .

(27) Dueker, S. R.; Lin, Y. M.; Buchholz, B. A.; Schneider, P. D.; Lame, M. W.; Segall, H. J.; Vogel, J. S.; Clifford, A. J. Journal of Lipid Research 2000, 41, $1790-1800$.

(28) Dingley, K. H.; Freeman, S. P.; Nelson, D. O.; Garner, R. C.; Turteltaub, K. W. Drug Metabolism and Disposition 1998, 26, 825-8.

(29) Turteltaub, K. W.; Dingley, K. H.; Curtis, K. D.; Malfatti, M. A.; Turesky, R. J.; Garner, R. C.; Felton, J. S.; Lang, N. P. Cancer Letters 1999, $143,149-55$. 
(30) Bennett, J. S.; BeIl, D. W.; Buchholz, B. A.; Kwok, E. S. C.; Vogel, J. S.; Morton, T. H. International Journal of Mass Spectrometry 1998, 180, 185-193. (31) Bennett, J. S. , University of California, 1999.

(32) Roberts, M. I.; Grant, P. G. Nuclear Instruments and Methods in Physics Research 1999, B 158, 24 - 30.

(33) Bench, G. B.; Balhorn, R.; Eriz, A. M. Nuclear Instruments and Methods in Physics Research 1995, B 99, 553 - 556.

(34) Patton, W. F. Electrophoresis 2000, 21, 1123-44.

(35) Shan, G.; Huang, W.; Gee, S. J.; Buchholz, B. A.; Vogel, J. S.; Hammock, B. D. Proceedings of the National Academy of Sciences of the United States of America 2000, 97, 2445-9.

(36) Hughey, B. J.; Klinkowstein, R. E.; Shefer, R. E.; Skipper, P. L.; Tannenbaum, S. R.; Wishnok, J. S. Nuclear Instruments \& Methods in Physics Research Section B-Beam Interactions With Materials and Atoms 1997, 123, 153158 .

(37) Congress, U. S. Federal Register 1991, 56.

This work was performed under the auspices of the U.S. Department of Energy by the University of California, Lawrence Livermore National Laboratory under Contract No. W-7405-Eng-48. 
University of California

Lawrence Livermore National Laboratory

Technical Information Department

Livermore, CA 94551

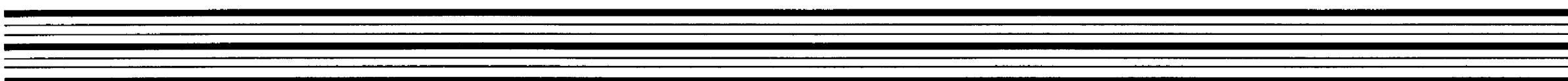

